\title{
Mixture Models of Human Resource Management Flexibility and Firm Performance
}

\author{
Ling $\mathrm{Xu}$ \\ College of Economics \& Management, \\ QingDao University of Science and Technology \\ QingDao,China \\ e-mail: xlxqh@163.com
}

\begin{abstract}
Numerical flexibility and functional flexibility are the two dimensions of human resource flexibility.The mixtures of the two dimensions form four models.They are $\mathrm{HH}$ model(high functional flexibility and high numerical flexibility), LL model ( low functional flexibility and low numerical flexibility), LH model(low functional flexibility and high numerical flexibility) and HL model (high functional flexibility and low numerical flexibility).The various mixture models differ from firm performance. Principal Component Analysis is used in this paper to find which model contributes much more to firm performance.It is demonstrated that in Chinese firms HL model is more effective for firm performance than other models.
\end{abstract}

Keywords- Functional Flexibility; Numerical Flexibility; HR Flexibility; Firm Performance

\section{INTRODUCTION}

Human resource flexibility has been seen as playing a key role in the drive for competitiveness and firm performance $^{[1]}$. Two dimensions are discussed in flexibility,that is,numerical flexibility and functional flexibility ${ }^{[2]}$.Numerical flexibility is the ability of firms to vary the amount of labour employed,by making use of parttime,temporary and seasonal employees,short fixed-term contracts,agency labour,etc.(Michie \& Quinn2001) ${ }^{[3]}$. Functional flexibility is the ability of firms to vary the amount and type of labour they use without resorting to the external labour market, and is accomplished primarily by having a labour force that is able to carry out a wide range of tasks-that is, the ability to move workers from one task to another.It has been demonstrated that human resource flexibility can influence firm performance (Blyton ,1997) ${ }^{[4]}$. But the two dimensions of flexibility construct four different mixtures ${ }^{[5]}$. Do the different mixtures contribute equally to firm performance? Further research is needed in this area.

So the purpose of this paper is to find the difference among the mixture models related to firm performance. In the first part four mixture models of flexibility are introduced.And then indicators to measure flexibility and firm performance are designed. And the next section shows the results. The final section concludes.

\section{Mixture Models of Human Resource FLEXIBILITY AND FIRM PERFORMANCE}

As for numerical flexibility and functional flexibility,four mixtures are suggested in this paper. HH model is defined as high functional flexibility and high numerical flexibility. LL model is defined as low functional flexibility and low numerical flexibility. LH model is defined as low functional flexibility and high numerical flexibility. HL model is defined as high functional flexibility and low numerical flexibility.In the four models,HH and LL model are balanced models.HL and LH models are unbalanced models. Figure 1 shows this typology of mixtures.

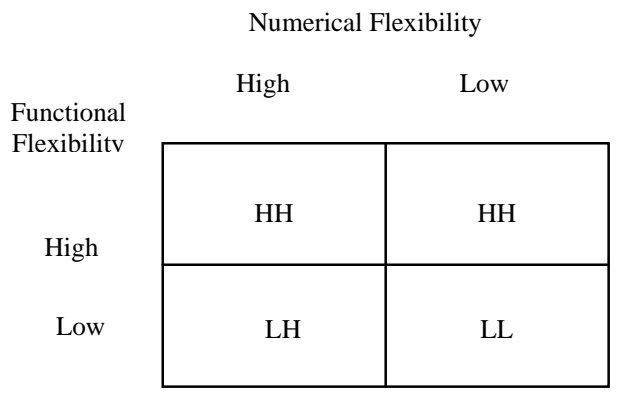

Figure 1. The Model of flexibility mixture

Functional flexibility and numerical flexibility may play different roles in firm performance.The difference in employee's ability should influence firm performance.So it is suggested that firm performance is better in $\mathrm{HH}$ model than in LL model. The performance between HL model and LH model is still in discussion.

Demonstration for Chinese firms will be carried out to test which model contributes much more to firm performance in the next section.

\section{MEASURES}

\section{A. Measures of Firm Performance and Human Resource Flexibility}

Objective and subjective measures are used in measuring firm performance and human resource flexibility. In addition, the data used in this analysis are collected at the firm level. The questionnaires are send by E-mail to top 
managers,human resource managers,product managers and marketing managers to get the details.

Five indicators are used in this paper to measure performance. Human resource $\operatorname{cost}\left({ }^{X_{1}}\right)\left(\right.$ Candelaria,2003) ${ }^{[6]}$, output per employee(( $\left.x_{2}\right)$ (Huselid,1995) ${ }^{[7]}$,product quality( $\left.X_{3}\right)$ (Candelaria,2003),product $\operatorname{cost}\left(\begin{array}{ll}X_{4} & \end{array}\right.$ (Arthur,1994) $^{[8]}$, customer satisfaction( $\quad X_{5} \quad$ ) (Candelaria,2003). All the measures are asked by one questions.

13 terms are designed to measure functional flexibility.After Principal Component Analysis,functional flexibility will be classified by dimensions and then to get a functional flexibility index to mearsure functional flexibility level.

Only one indicator is used in this paper to mearsure numerical flexibility.That is employees in short term contracts as a percentage of total employees. This indicator is directly used to measure numerical flexibility level.

\section{B. Principal Component Analysis}

Principal Component Analysis (PCA) is used to know how many dimensions are in functional flexibility and firm ferpormance. Mixture models will be defined and firm performance will be ranked by scores according to the results of PCA. SPSS 16.0 tool is used for testing.

\section{1) Reliability Test}

Before PCA, reliability test should be carried out to know whether the terms are suitable for PCA. KMO and Bartlett's Test are the best tools for reliability test.As shown in table 1 and table 2, KMO and Bartlett's Test shows that both the terms for testing firm performance and functional flexibility are suitable for PCA.

TABLE I. KMO AND BARTLETT'S TEST FOR FIRM PERFORMANCE

\begin{tabular}{|c|c|c|}
\hline \multicolumn{2}{|c|}{ Kaiser-Meyer-Olkin Measure of Sampling Adequacy. } & .572 \\
\hline Bartlett's Test of Sphericity & Approx. Chi-Square & 160.819 \\
\hline & df & 10 \\
\hline & Sig. & .000 \\
\hline
\end{tabular}

TABLE II. KMO AND BARTLETT'S TEST FOR FUNCTIONAL FLEXIBILITY

\begin{tabular}{|c|c|c|}
\hline \multicolumn{2}{|c|}{ Kaiser-Meyer-Olkin Measure of Sampling Adequacy. } & .881 \\
\hline Bartlett's Test of Sphericity & Approx. Chi-Square & 725.547 \\
\hline & df & 78 \\
\hline & Sig. & .000 \\
\hline
\end{tabular}

2) Factors in Performance

Two factors can be extracted in terms of firm performance and the two factors explain $72.128 \%$ of the variables as shown in table 3 . The two factors are named cost $\left(F_{1}\right)$ and output $\left(F_{2}\right)$. And integration of them $\left(F_{p}\right)$ can measure firm performance.
After extracted the two factors,Communalities are all above 0.7 which implies that information losed little and factors extracted are perfect.

TABLE III. TOTAL VARIANCE EXPLAINED FOR FIRM PERFORMANCE

\begin{tabular}{|c|c|c|c|}
\hline \multirow{2}{*}{ Component } & \multicolumn{3}{|c|}{ Initial Eigenvalues } \\
\hline & Total & \% of Variance & $\begin{array}{c}\text { Cumulative } \\
\text { \% }\end{array}$ \\
\hline 1 & 2.196 & 43.915 & 43.915 \\
\hline 2 & 1.411 & 28.213 & 72.128 \\
\hline 3 & .708 & 14.166 & 86.294 \\
\hline 4 & .454 & 9.086 & 95.380 \\
\hline 5 & .231 & 4.620 & 100.000 \\
\hline \multicolumn{4}{|c|}{ To be Continued } \\
\hline
\end{tabular}

\begin{tabular}{|c|c|c|c|}
\hline Component & \multicolumn{3}{|c|}{ Rotation Sums of Squared Loadings } \\
\hline & Total & \% of Variance & $\begin{array}{c}\text { Cumulative } \\
\%\end{array}$ \\
\hline 1 & 2.061 & 41.228 & 41.228 \\
\hline 2 & 1.545 & 30.900 & 72.128 \\
\hline 3 & & & \\
\hline 4 & & & \\
\hline 5 & & & \\
\hline
\end{tabular}

Extraction Method: Principal Component Analysis. Rotation Method: Varimax with Kaiser Normalization.

TABLE IV. ROTATED COMPONENT MATRIX(A)

\begin{tabular}{|c|c|c|}
\hline \multirow{2}{*}{} & \multicolumn{2}{|c|}{ Component } \\
\cline { 2 - 3 } & 1 & 2 \\
\hline Human resource cost $\left(X_{1}\right)$ & -.055 & .833 \\
\hline Output per employee $\left(X_{2}\right)$ & .632 & .352 \\
\hline Product quality $\left(X_{3}\right)$ & .918 & -.058 \\
\hline Product cost $\left(X_{4}\right)$ & .180 & .850 \\
\hline Customer Satisfaction $\left(X_{5}\right)$ & .885 & .021 \\
\hline
\end{tabular}

The variables are loaded differently in the two factors as seen in table 4.

So the factors are scored as follows.

$$
\begin{aligned}
& F_{1}=-0.055 x_{1}+0.632 x_{2}+0.918 x_{3}+0.18 x_{4}+0.885 x_{5} \\
& F_{2}=0.833 x_{1}+0.352 x_{2}-0.058 x_{3}+0.85 x_{4}+0.021 x_{5} \\
& F_{p}=\left(0.412 F_{1}+0.309 F_{2}\right) / 0.72128
\end{aligned}
$$

3) Factors in Functional Flexibility

As show in table 5,three distinct sub-dimensions of HR functional flexibility have been identified, namely ,training( $F_{f 1}$ ), multi-learning $\left(F_{f 2}\right)$ and self- 
determination $\left({ }^{F_{f 3}}\right)$. The three dimensions explain $65.837 \%$ of the iterms.

TABLE V. TOTAL VARIANCE EXPLAINED FOR FUNCTIONAL FLEXIBILITY

\begin{tabular}{|c|c|c|c|}
\hline \multirow[t]{2}{*}{ Component } & \multicolumn{3}{|c|}{ Initial Eigenvalues } \\
\hline & Total & $\%$ of Variance & Cumulative \% \\
\hline 1 & 6.121 & 47.085 & 47.085 \\
\hline 2 & 1.368 & 10.519 & 57.604 \\
\hline 3 & 1.070 & 8.233 & 65.837 \\
\hline 4 & .916 & 7.046 & 72.883 \\
\hline 5 & .607 & 4.667 & 77.550 \\
\hline 6 & .581 & 4.473 & 82.023 \\
\hline 7 & .456 & 3.510 & 85.533 \\
\hline 8 & .392 & 3.017 & 88.550 \\
\hline 9 & .375 & 2.886 & 91.436 \\
\hline 10 & .351 & 2.704 & 94.140 \\
\hline 11 & .295 & 2.271 & 96.411 \\
\hline 12 & .280 & 2.155 & 98.566 \\
\hline 13 & .186 & 1.434 & 100.000 \\
\hline
\end{tabular}

\begin{tabular}{|c|c|c|c|}
\hline Component & \multicolumn{3}{|c|}{ Rotation Sums of Squared Loadings } \\
\hline & Total & \% of Variance & Cumulative \% \\
\hline 1 & 3.618 & 27.831 & 27.831 \\
\hline 2 & 2.789 & 21.451 & 49.282 \\
\hline 3 & 2.152 & 16.554 & 65.837 \\
\hline
\end{tabular}

Extraction Method: Principal Component Analysis.

By SPSS tools,Communalities of the three dimensions are all above 0.7 which implies that information losed little and factors extracted are perfect.

Cronbach's Alpha of the three dimensions is $0.830,0.680$ and 0.882 respectively. That means the liability is in a high level.

TABLE VI. ROTATED COMPONENT MATRIX(A) FOR FUNCTIONAL FLEXIBILITY

\begin{tabular}{|c|c|c|c|}
\hline \multirow{2}{*}{} & \multicolumn{3}{|c|}{ Component } \\
\cline { 2 - 4 } & $\mathbf{1}$ & $\mathbf{2}$ & $\mathbf{3}$ \\
\hline A1 & .228 & .370 & .589 \\
\hline A2 & .417 & .661 & .193 \\
\hline A33 & .172 & .831 & .114 \\
\hline A4 & .685 & .394 & .179 \\
\hline A5 & .051 & .736 & .387 \\
\hline A6 & .660 & .268 & .370 \\
\hline A7 & .345 & .756 & .123 \\
\hline
\end{tabular}

\begin{tabular}{|c|c|c|c|}
\hline A8 & .794 & .232 & .091 \\
\hline A9 & .724 & .177 & -.008 \\
\hline A10 & .745 & .029 & .372 \\
\hline A11 & .725 & .198 & .356 \\
\hline A12 & .301 & .219 & .770 \\
\hline A13 & .101 & .104 & .745 \\
\hline
\end{tabular}

Extraction Method: Principal Component Analysis.

$$
\begin{aligned}
& F_{f 1}=0.228 A_{1}+0.417 A_{2}+0.172 A_{3}++\ldots .0 .101 A_{13}(4) \\
& F_{f 2}=0.37 A_{1}+0.661 A_{2}+0.831 A_{3}++\ldots .0 .104 A_{13}(5) \\
& F_{f 3}=0.589 A_{1}+0.193 A_{2}+0.114 A_{3}++\ldots .0 .745 A_{13}(6) \\
& F_{f}=\left(0.28 F_{f 1}+0.21 F_{f 2}+0.17 F_{f 3}\right) / 0.65837
\end{aligned}
$$

According to this,scores of functional flexibility can be calculated for each firm.

\section{RESUlTS}

In all the samples,mean of numerical flexibility is 0.185 . Mean of functional flexibility is 3.56.So four mixture models are identified according to mean as mentioned in the second part.

As the categorization shows that $19.2 \%$ of firms are involved in HH model, 28.2\% involved in HL model, 30.8\% involved in LH model and 21.8\% involved in LL model.

TABLE VII. FIRM PERFORMANCE IN DIFFERENT MODELS

\begin{tabular}{|c|c|c|c|c|}
\hline $\begin{array}{c}\text { Mixture } \\
\text { Models }\end{array}$ & $F_{1}$ & $F_{2}$ & $F_{p}$ & Top List \\
\hline $\begin{array}{c}\text { HH } \\
\text { Model }\end{array}$ & 10.8 & 8.1 & 9.86 & 2 \\
\hline $\begin{array}{c}\text { LH } \\
\text { Model }\end{array}$ & 8.6 & 6.9 & 7.8999 & 4 \\
\hline $\begin{array}{c}\text { HL } \\
\text { Model }\end{array}$ & 11.3 & 8.6 & 9.9099 & 1 \\
\hline $\begin{array}{c}\text { LL } \\
\text { Model }\end{array}$ & 9.4 & 7.3 & 8.46 & 3 \\
\hline
\end{tabular}

According to the method mentioned above, two factors of firm performance and integrated index are scored as seen in table 7.

It is showed that cost (F1) is high in HL model and HH model. Output(F2) is also high in HL model and HH model. HL model performs a little higher than $\mathrm{HH}$ model.Firms with high fuctional flexibility all perform high than firms with low functional flexibility.Firms in LH model perform the lowest in the four models.

\section{CONCLUSIONS}

How does HR flexibility contribute to firm performance has been attracted increasing attentions in recent years.This paper contributes to study firm performance by different mixture models of HR flexibility.

As demonstrated, functional flexibility contributes much more in firm performance and numerical contributes much less for firm performance.Firms in HL model perform best in the foure models.So there is some benefits for firms to mix functional flexibility and numerical flexibility. 


\section{ACKNOWLEDGMENT}

This paper is supported by the following funds: the Planning topics of the Ministry of Education of China(Grant No. 11YJA630207); The Soft Science Research Program of ShanDong Province of China(Grant No. 2011RKGB7058, 2011RKGB4014); The topics of Office of Education of ShonDong Province of China (Grant No. J12WF84); The topics of National Bureau of statistics of China (Grant No. 2011LY075); The topics of Cultural Hall of ShanDong Province of China(Grant No. 2012E1010)

\section{REFERENCES}

[1] Hang-Yue Ngo and Raymond Loi, "Human resource flexibility, organizational culture and firm performance”,The International Journal of Human Resource Management,vol.19,pp:1654-1659 ,Sep 2008.

[2] Lau,C.M., and Ngo,H.Y., "The HR System,Organizational Culture, and Product Innovation”, International BusinessReview, vol13,pp.:685-703, Dec 2004.
[3] Jonathan Michie and Maura Sheehan-Quinn, "Labour Market Flexibility, human Resource Management and Corporate Performance”, British Journal of Management, vol. 12, pp:287306, 2001

[4] Blyton P, MorisJ."HRM and the limits of flexibility. Reassessing Human Resource Management "Eds.Blyton,Turnbull J,Sage Publications.London: pp: 116-130, 1997

[5] Bhattacharya. "People as A Competitive Edge :Examining the Empirical Relationship between Human Resource Flexibility and Firm Performance”. Syracuse University,2000

[6] Candelaria Ruiz-Santos, Josefa Ruiz-Mercader, "The use of contractual working time flexibility by Spanish SMEs”,Personnel Review, vol2, pp:164-186, 2003

[7] Huselid M.”The Impact of Human Resource Management Practices on Turnover, Productivity, and corporate financial performance”.AcademyofManagement Journal, vol38 pp:635-672, 1995

[8] Arthur J B.”Effects of the human resource systems on manufacturing performance and turnover". Academy of Management Journal, Vol 37, pp:670-687, 1994 